\title{
Application of Kansei Engineering and Box-Behnken response surface methodology for shape parameter design: A case study of wine glass
}

\author{
Chaiwat KITTIDECHA * and Ashuboda Chandrajith MARASINGHE* \\ * Information Science and Control Engineering, Nagaoka University of Technology, \\ 1603-1 Kamitomioka, Nagaoka-shi, Niigata-ken, 940-2188, Japan \\ E-mail: s147001@stn.nagaokaut.ac.jp
}

Received 8 June 2015

\begin{abstract}
Product appearance has become a more important influence on customers' preference in regards to product purchase. Not only do customers take into account functionality and cost, but also on aesthetic and affection value. Kansei engineering (KE) utilizes a product design methodology which translates a customers' perception regarding feeling and emotion on appearance of a product into a product's design parameters. This study applied KE methodology to determine customer emotion on the shape of wine glasses and the optimal precise design parameters to obtain customer satisfaction. This study was performed using a four-factor and three-level Box-Behnken design under response surface methodology (RSM). The data obtained from the experiments were analyzed by analysis of variance. Furthermore, the data was fitted to a second-order polynomial equation using multiple regression analysis. The effects of four parameters of wine glass, namely the rim's width $(A)$, the bowl's width $(B)$, the bowl's height $(C)$ and the stem's height $(D)$ on the surface potential of five Kansei words, namely modern, quality, durable, ease of drinking and ease of handle were examined. The optimal model of wine glass design was controlled at $A=90 \mathrm{~mm}, B=61.82 \mathrm{~mm}, C=126.67 \mathrm{~mm}$ and $D=61.97 \mathrm{~mm}$, respectively. The results of RSM indicate that the proposed shape design models can interpret all of customers' emotion about a product which in this case is a wine glass. Finally, this study provides useful understanding for shape parameter design and this method can be applied to a variety of design cases.
\end{abstract}

Key words : Kansei engineering, Response surface methodology, Box-Behnken design, Shape parameter, Wine glass

\section{Introduction}

The importance of physical appearance of products has dramatically increased in two decades as the society and market have become more vulnerable for the aesthetic quality of the products (Yadav, et al., 2013). Every company competing in the market has to focus on this issue, and they have improved their products to enhance consumer satisfaction. A product with an aesthetic design that matches with customer preference are especially chosen when product alternatives are similar in terms of functions and price (Tang, et al., 2013). Generally, designers may not fully understand customer needs because the design accomplishments between the designer and his or her customers are different. Kansei Engineering (KE) utilizes a product development methodology which translates customer feelings and impressions into product design parameters (Nagamachi, 1995). KE has seen a growing diffusion in the last years among product designers. KE has carried out several studies in order to translate customer emotions into concrete shape features. For example, Shieh and Yeh (2013) determined the correlation between the form of running shoes and consumer emotional responses. Schütte (2013) mapped the affective impression of chocolate bars exterior. Yanagisawa and Fukuda (2007) developed a design methodology for an automobile sideboard shape design using interactive reduct evolutional computation and KE. However, it is believed that these studies are unable to depict the geometries precisely because 
there are several problems that have to be overcome in order to determine a set of design parameters as the design parameters of a product shape should be combined in all of significant customer emotions. One of the most effective tools for optimizing the process when many factors and interactions affect the desired response is response surface methodology (RSM). RSM, first introduced by Box and Wilson (1951), has become an important tool in process and product development. RSM consists of techniques from mathematical optimization and statistics that are used to improve existing processes or develop new processes. Then, RSM can be used to obtain optimal condition that resulting in a better overall product. RSM using with Box-Behnken design (BBD) was conducted due to its: 1) ability to process multiple variables, 2) capability of evaluating the interactions between factors, 3) avoidance of extreme conditions, and 4) less resource demand (Mo, et al., 2014). Several studies on the RSM-BBD have been conducted for the optimization of process parameters. For example, styrene recovery from waste polystyrene (Mo, et al., 2014), the aqueous extraction of betalain from beetroot (Swamy, et al., 2014), catalysts of sodium silicate and cadmium oxide (Moradi, et al., 2013) and modeling of some Turkish coals (Aslan and Cebeci, 2007). However, some researchers used design of experiment (DOE) and KE for the physical appearance of products design. For instance, Lanzotti, et al. (2015) determined the optimal seats design using KE, DOE and ordinal logistic regression. Yadav, et al. (2013) which used RSM-Taguchi design to find the optimum level of the car shape parameters. Sutono, et al. (2012) conducted KE and Taguchi design to determine the optimal design parameters of the office chair. Widiyati and Aoyama (2011) studied KE in PET Bottle using Taguchi methods and artificial neural network (ANN). Lai, et al. (2005) applied the Taguchi design to optimize the car shape design. Chen and Chuang (2008) combined grey relational analysis with the Taguchi method to optimize shape of mobile phone. Nordgren (2007) employed Taguchi design, principle component analysis (PCA), ANN and Kansei design to build a car model. Nordgren and Aoyama (2005) created form impressions of a car by Taguchi method, factor analysis and neural network. Therefore, it shows that the study on RSM-BBD approach in $\mathrm{KE}$ is not used to design shape of product. Most previous works applied Taguchi method to design the experiment. In addition, it is the first time to apply these methods for design product in Thailand and it can be the prototype of the various design cases. In this study, a wine glass design was selected as a case study to illustrate how applied KE and RSM-BBD used to parameterize design of shape product. A study on this product was one of samples that Petiot and Yannou (2003) presented in a design of table glasses using PCA and semantic differential method. They rated and ranked the new prototypes according to the existing products. Differ from theirs study, results from RSM are high precision and accuracy which multi-optimize with multiple customer emotions. Furthermore, the cultural difference in nation differs significantly in terms of demand, consumer behavior, product requirements, and marketing strategies (Drouart and Alarie 2013). Especially, glass industry is one of the high economic value added industries in Thailand (Small and medium industrial institute, 2011). The aim of this study is to determine the optimal product shape parameters of wine glass base on customer emotions.

\section{Theoretical background 2.1 Kansei Engineering}

$\mathrm{KE}$ is an important product design methodology. It translates customer impressions, feelings and needs on existing products or concepts to design solutions and parameters. In addition, it shows how Kansei is translated into product design (Schütte, 2005). Therefore, the design by KE parametrically links a customer's emotional response to the products or services with their properties and characteristics. Hence, the products can be designed to bring forward the intended feeling of customer. There are four main approaches in measuring the emotion for KE: 1) statistical scaling, 2) magnitude estimation, 3) Likert scale, and 4) semantic differentials method (Nagamachi, 2011). Kansei words that described semantic expressions were selected from the spanning the semantic space (Wikipedia, 2015b). There are also several approaches in analyzing data such as statistical approach, soft computing approach, and mathematical model approach, which are widely known in KE classification type I to type VI (Schütte , 2002).

\subsection{Box-Behnken Design}

In the optimization procedure, the optimum operating conditions are achieved by using complex experimental designs, such as Doehlert Matrix, Central Composite Designs, and BBD. BBD is a class of rotatable or nearly rotatable second-order designs based on three-level incomplete factorial design (Ferreira, et al., 2007). The number of 
experiments $(N)$ required for BBD is defined as follow:

$$
N=2 k(k-1)+C_{0}
$$

where $k$ is number of factors and $C_{o}$ is the number of central points. The advantage of the BBD is that it does not contain combinations for which all factors are simultaneously at their highest or lowest levels. Thus, these designs are useful in eliminating experiments performed under extreme conditions, for which unsatisfactory results might occur (Hasan, et al., 2010).

\subsection{Response Surface Methodology}

RSM is a collection of statistical and mathematical techniques that are used for developing, improving and optimizing process. It has useful applications in design and developing of existing product design (Bandyopadhyay and Bhattacharya, 2014). Most widespread applications of RSM are found in industrial sector, especially when there are several input variables potentially influence the key point performance or quality characteristic of the product or process (Myers and Montgomery, 2002). This performance measurement or quality characteristic is called the response. Basically, the response is measured on a continuous scale, even though attribute responses, rank, and sensory responses are not unusual. Most applications of RSM will involve more than one response. In general, either a linear or second-order polynomial expression is sufficient for RSM technique to model the observed response (Box and Behnken, 1960).

$$
Y=\beta_{0}+\sum_{i=1}^{k} \beta_{i} X_{i}+\sum_{i=1}^{k} \beta_{i i} X_{i}^{2}+\sum_{i=1}^{k-1} \sum_{j=1}^{k} \beta_{i j} X_{i} X_{j}+\varepsilon
$$

where $Y$ is the response variables used in the response surface design; $k$ is number of factors; $\beta_{0}$ is the model constant; $\beta_{i}(i=1,2, \ldots, k)$ represents the linear coefficient; $\beta_{i j}(i=1,2, \ldots, k ; j=1,2, \ldots, k)$ represents the quadratic coefficient; $X_{i}$ and $X_{j}$ the coded independent variables and $\varepsilon$ is the statistical error.

\section{Methodology}

This study applied KE and RSM based on model procedure presented by Schütte, et al., (2005). The procedure of this study is represented in Fig. 1. This procedure is presented as follows.

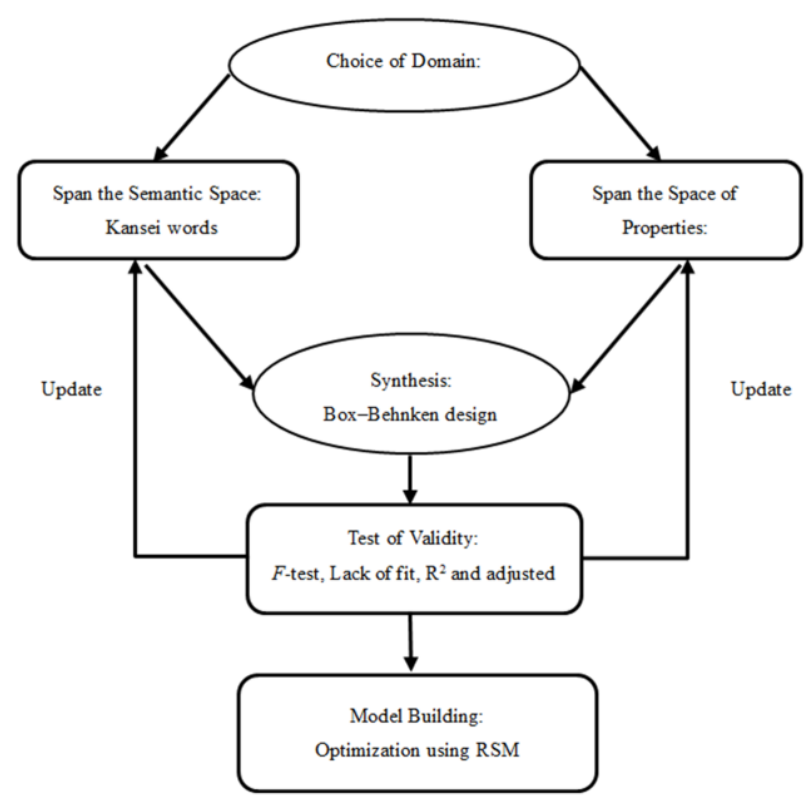

Fig. 1 Research methodology. 


\subsection{Choice of domain}

A wine glass was selected as the product domain. The sample size of the study was 30 participants. The participants were wine drinkers who had been using wine glasses for a long time.

\subsection{Span the semantic space}

Kansei words were collected from advertisements, internet videos, magazines and literature reviews. Some of these Kansei words that were unclear, ambiguous or have the same meaning were omitted in the screening step. After discussions with the professionals and experts in product design from Rajamangala University of Technology Lanna (Thailand), five highly relevant words were finally determined in the form of Kansei words to enhance the participants' feelings, namely 1) modern, 2) quality, 3) durable, 4) ease of drinking, and 5) ease of handle. These Kansei words were represented as the observed response $(Y)$ for RSM technique as the output parameters in Fig.2.
Input
1) the rim's width $(A)$
2) the bowl's width $(B)$
3) the bowl's height $(C)$
4) the stem's height $(D)$

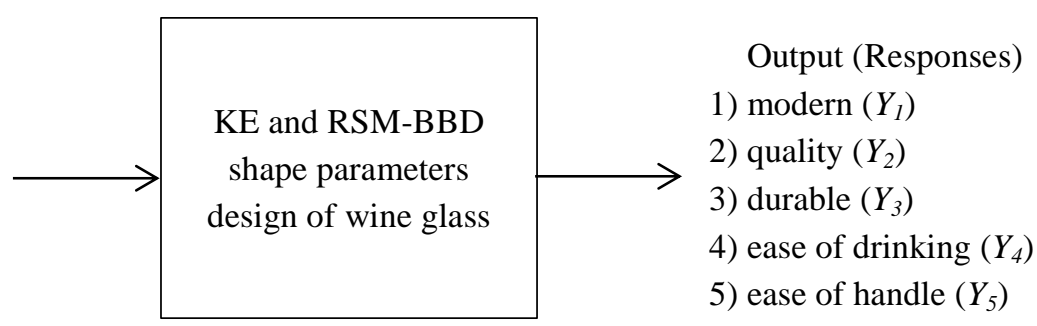

Fig. 2 Input-output parameters of KE and RSM-BBD shape parameters design of wine glass.

\subsection{Span the space of properties}

The product shape parameters which can have an impact on the emotional response are identified as the control factors in the BBD experiments. Generally, there are four parts of a wine glass, namely, 1) the foot, 2) the stem, 3) the bowl and 4) the rim as shown in Fig.3 (Webstaurantstore, 2015). The position of the identified shape features with respect to the overall wine glass design is described in Fig.3. These design parameters were represented as the independent variables $(X)$ as the input parameters in Fig. 2 The shape features that are insignificant factors for evaluation of customer feelings were kept fixed and excluded from the design parameter settings such as the stem's width and the foot's width. In this study, a four-factor and three-level BBD design of experiment was used in conjunction with RSM of analysis. Each shape design parameter was chosen for three different levels as shown in Table 1. Here $-1,0$, and +1 represent low, medium, and high levels, respectively.

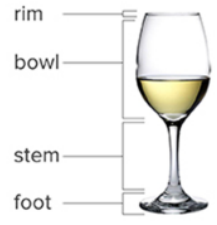

Fig. 3 Parts of wine glass (Webstaurantstore, 2015).

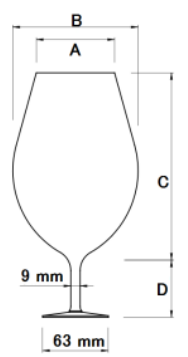

Fig. 4 Shape design parameters for wine glass design. 
Table 1 Shape design parameters and their levels according to Box-Behnken design.

\begin{tabular}{lcccc}
\hline \hline \multicolumn{1}{c}{ Shape design parameters } & Symbol & & Level \\
& & & & 0 \\
\cline { 2 - 5 } & & -1 & 75 & +1 \\
\hline the rim's width $(\mathrm{mm})$ & $A$ & 30 & 75 & 120 \\
\hline the bowl's width $(\mathrm{mm})$ & $B$ & 30 & 100 & 120 \\
\hline the bowl's height $(\mathrm{mm})$ & $C$ & 20 & 55 & 85 \\
\hline the stem's height $(\mathrm{mm})$ & $D$ & 25 & \\
\hline \hline
\end{tabular}

\subsection{Synthesis \\ 3.4.1 Experimental design}

The BBD with two center point was performed. This design requires 26 experimental runs from Eq. (1) $(N=26$; $k=4 ; C_{o}=2$ ). The experimental setup shown in Table 2 was obtained from a software package MINITAB (Minitab, 2010). The shape design model generated based on BBD as shown in Fig.5.

\subsubsection{Data collection process}

The participants were requested to evaluate the 26 experimental runs for five Kansei words evaluation using a five level Likert scale (from $1=$ definitely disagree to $5=$ definitely agree). A questionnaire was distributed in order to classify the relationship between the shape design parameters and customer emotions. These surveys were conducted in Chiang Mai, Thailand.

\subsection{Test of validity}

The statistical significance of Eq. (2) was checked by F-test, and the analysis of variance (ANOVA) was used to test the adequacy and fitness of the models. ANOVA is a basic statistical technique that subdivides the total variation of a data set into component parts associated with sources of variation for testing hypotheses on the variables of the model (ASQ, 2015). Fisher's test was conducted to analyze the significance of each independent variable or design parameter. The $F$ value is the ratio of two scaled sums of squares reflecting different sources of variability (Wikipedia, 2015a). It indicates the influence of each shape design parameter on the tested model. The high $F$ value indicates that the variation in the responses can be interpreted by the regression equation (Swamy, et al., 2014). The $p$ values of model terms greater than 0.05 indicate that the model terms are not significant whereas the values less than 0.05 indicate that the model terms are significant. "Lack of fit" illustrates the lack of fit index of the fitted model. The fitted model is good if lack of fit is insignificant (Lai, et al., 2014). The coefficient of determination $\left(\mathrm{R}^{2}\right)$ and adjusted $\mathrm{R}^{2}$ were computed to verify the sufficiency and fitness of the model. The high $\mathrm{R}^{2}$ and adjusted- $\mathrm{R}^{2}$ coefficient represent the good relationships between the experimental variables and predicted values of the response (Fu, et al., 2012).

\subsection{Model building}

RSM associates the optimal values of explanatory variables. Composite desirability (D) evaluates how the settings optimize a set of responses overall. Desirability has a range of zero to one. One represents the ideal case; zero indicates that one or more responses are outside their acceptable limits (Minitab, 2010). In this study, the shape design parameters of wine glass could be simulated with the multi objective optimization. The maximum predicted values for shape features as well as the maximum values of five Kansei words could be optimized from RSM. 
Table 2 RSM-BBD design matrix.

\begin{tabular}{|c|c|c|c|c|c|c|c|c|}
\hline \multirow[t]{2}{*}{ Run } & \multicolumn{4}{|c|}{ Actual shape design parameters } & \multicolumn{4}{|c|}{ Coded factors } \\
\hline & $\begin{array}{l}\text { the rim's } \\
\text { width } \\
(\mathrm{mm})\end{array}$ & $\begin{array}{l}\text { the } \\
\text { bowl's } \\
\text { width } \\
(\mathrm{mm})\end{array}$ & $\begin{array}{l}\text { the } \\
\text { bowl's } \\
\text { height } \\
(\mathrm{mm})\end{array}$ & $\begin{array}{l}\text { the } \\
\text { stem's } \\
\text { height } \\
(\mathrm{mm})\end{array}$ & $A$ & $B$ & $C$ & $D$ \\
\hline 1 & 75 & 120 & 180 & 55 & 0 & 1 & 1 & 0 \\
\hline 2 & 120 & 120 & 100 & 55 & 1 & 1 & 0 & 0 \\
\hline 3 & 30 & 75 & 20 & 55 & -1 & 0 & -1 & 0 \\
\hline 4 & 75 & 75 & 100 & 55 & 0 & 0 & 0 & 0 \\
\hline 5 & 75 & 120 & 20 & 55 & 0 & 1 & -1 & 0 \\
\hline 6 & 120 & 75 & 100 & 85 & 1 & 0 & 0 & 1 \\
\hline 7 & 75 & 30 & 20 & 55 & 0 & -1 & -1 & 0 \\
\hline 8 & 120 & 75 & 180 & 55 & 1 & 0 & 1 & 0 \\
\hline 9 & 75 & 30 & 180 & 55 & 0 & -1 & 1 & 0 \\
\hline 10 & 75 & 30 & 100 & 85 & 0 & -1 & 0 & 1 \\
\hline 11 & 30 & 75 & 100 & 85 & -1 & 0 & 0 & 1 \\
\hline 12 & 75 & 120 & 100 & 25 & 0 & 1 & 0 & -1 \\
\hline 13 & 120 & 30 & 100 & 55 & 1 & -1 & 0 & 0 \\
\hline 14 & 30 & 75 & 180 & 55 & -1 & 0 & 1 & 0 \\
\hline 15 & 75 & 75 & 180 & 85 & 0 & 0 & 1 & 1 \\
\hline 16 & 30 & 120 & 100 & 55 & -1 & 1 & 0 & 0 \\
\hline 17 & 120 & 75 & 100 & 25 & 1 & 0 & 0 & -1 \\
\hline 18 & 75 & 75 & 20 & 85 & 0 & 0 & -1 & 1 \\
\hline 19 & 75 & 75 & 100 & 55 & 0 & 0 & 0 & 0 \\
\hline 20 & 30 & 30 & 100 & 55 & -1 & -1 & 0 & 0 \\
\hline 21 & 75 & 30 & 100 & 25 & 0 & -1 & 0 & -1 \\
\hline 22 & 120 & 75 & 20 & 55 & 1 & 0 & -1 & 0 \\
\hline 23 & 75 & 75 & 180 & 25 & 0 & 0 & 1 & -1 \\
\hline 24 & 75 & 120 & 100 & 85 & 0 & 1 & 0 & 1 \\
\hline 25 & 75 & 75 & 20 & 25 & 0 & 0 & -1 & -1 \\
\hline 26 & 30 & 75 & 100 & 25 & -1 & 0 & 0 & -1 \\
\hline
\end{tabular}

\section{Result and discussion}

\subsection{Box-Behnken design and analysis}

RSM is an empirical modeling technique used to evaluate the relationship between the design parameters and the customer emotions that were evaluated by Kansei words. The results of the emotional evaluation are tabulated in Table 3. The following five second-order polynomial equations encoded form was established to explain the emotional Kansei words, namely modern, quality, durable, ease of drinking and ease of handle, respectively.

$$
\begin{aligned}
Y_{1}=2.385-0.10167 A-0.49333 B-0.06833 C+0.03333 D+1.06667 A^{2}+0.35667 B^{2} \\
\quad+0.00667 C^{2}+0.09167 D^{2}-0.1225 A B+0.07 A C-0.0675 A D-0.5125 B C \\
\quad-0.175 B D+0.0625 C D
\end{aligned}
$$

$$
\begin{aligned}
Y_{2}=3.49 & +0.465 A+0.45417 B+0.215 C+0.23917 D-0.74125 A^{2}+0.235 B^{2} \\
& +0.15375 C^{2}+0.12 D^{2}-0.0425 A B+0.165 A C+0.2525 A D+0.1725 B C \\
& +0.1575 B D+0.1725 C D
\end{aligned}
$$




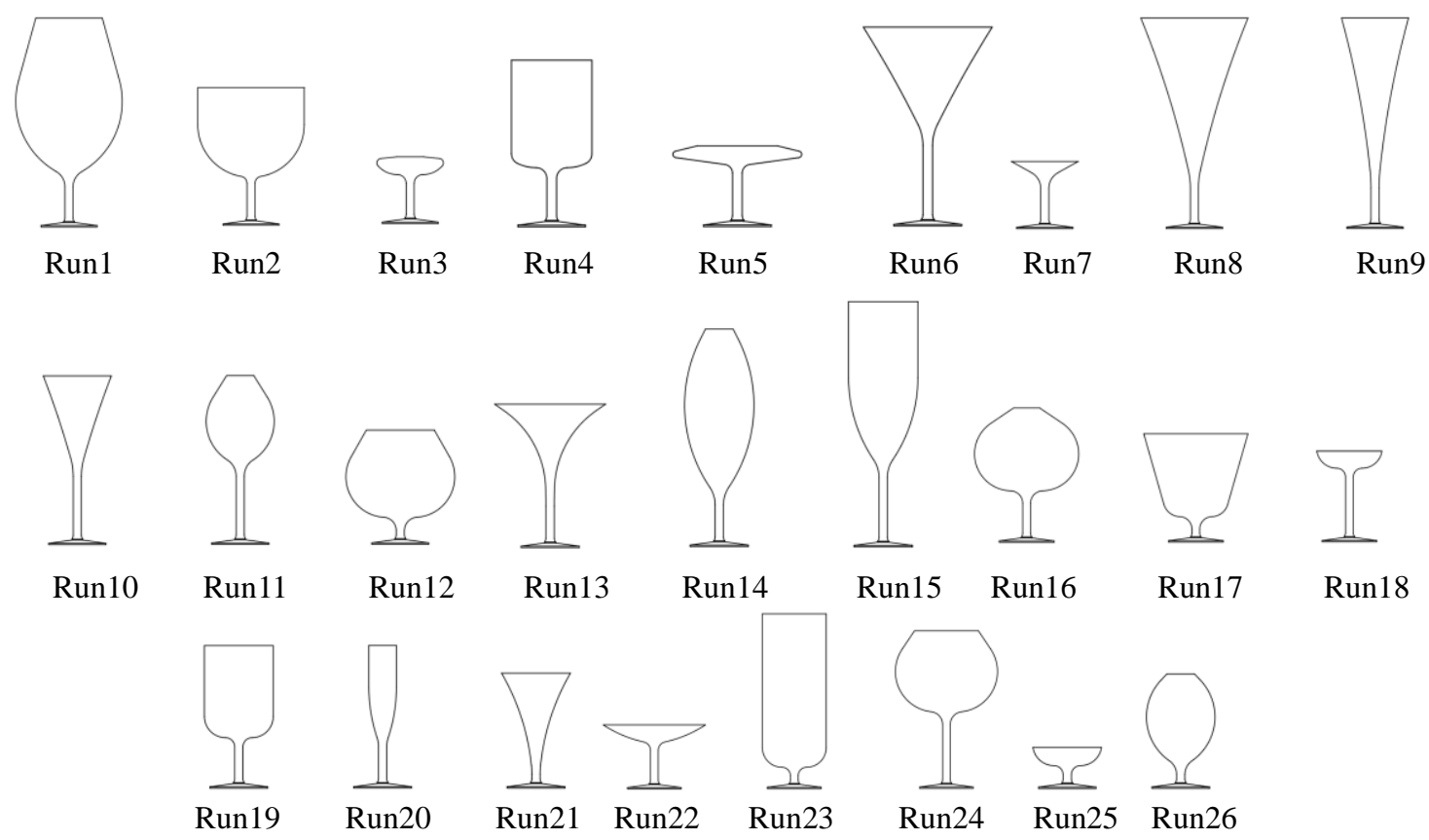

Fig. 5 Shape design models of wine glass generated based on BBD.

$$
\begin{aligned}
Y_{3}=4.525 & -0.64833 A+0.05417 B+0.5725 C+0.02333 D-0.69875 A^{2}-0.905 B^{2} \\
& -1.005 C^{2}-0.44375 D^{2}+0.0775 A B-0.265 A C+0.0175 A D+0.27 B C \\
& -0.105 B D-0.0025 C D \\
Y_{4}=4.675 & +0.40833 A-0.10417 B+0.05167 C-0.06583 D-1.10042 A^{2}-0.48417 B^{2} \\
& -0.37792 C^{2}-0.56667 D^{2}-0.015 A B-0.02 A C+0.035 A D+0.29 B C \\
+ & 0.2525 B D-0.105 C D \\
Y_{5}=4.39+ & 0.660833 A-0.11167 B+0.02 C+0.5125 D-0.62333 A^{2}-0.08958 B^{2} \\
& -0.17708 C^{2}-1.14583 D^{2}+0.1775 A B-0.0175 A C-0.1175 A D-0.1 B C \\
& +0.0225 B D-0.0225 C D
\end{aligned}
$$

Where $Y_{1}, Y_{2}, Y_{3}, Y_{4}$ and $Y_{5}$ are the emotional quality characteristics of modern, quality, durable, easy of drinking, easy of handle, respectively; $A, B, C$ and $D$ are the coded values of design parameters including the rim's width, the bowl's width, the bowl's height and the stem's height, respectively. It could be observed from the coefficients in Eq. (3)-(7) that the emotion of quality, easy of drinking and easy of handle increased with the rim's width $(A)$ and the bowl's height $(C)$, whereas Kansei words "quality" and “durable" increased with the bowl's width $(B)$. The stem's height $(D)$ was affected the response of modern, quality, durable and ease of handle to increasing except ease of drinking. Also, these mathematical models could help to predict the overall shape feature of wine glass with different customer emotions.

Statistical significances of Eq. (3)-(7) were checked by $F$ test, and the summaries of the analysis of variance (ANOVA) for response surface quadratic models are shown in Tables 4 . The model was further checked by $F$ value, $p$ value, Lack-of-Fit, $\mathrm{R}^{2}$ and adjusted $\mathrm{R}^{2}$. As shown in Table 4 , the $p$ values of all the linear and quadratic model were significant for all of five Kansei words at $5 \%(p<0.05)$. The values of the response for lack of fit $(p>0.05)$ revealed that it was not significant. $\mathrm{R}^{2}$ values that were close to 1 referred to the better correlations between the shape design parameters and Kansei words values. The determination coefficients $\left(\mathrm{R}^{2}\right)$ were calculated as $0.9643,0.9689,0.8700$, 0.8732 and 0.9081 , respectively. Therefore, the relations between the experimental and predicted values of the response were good. The values of adjusted $\mathrm{R}^{2}$ were ccomputed to be $91.89 \%, 92.92 \%, 70.46 \%, 71.18 \%$ and $79.12 \%$ for the five models. Only about $8.11 \%, 7.08 \%, 29.54 \%, 28.82 \%$ and $20.88 \%$ of the total variations could not be explained by the models. 
Table 3 Experimental responses of shape design parameters.

\begin{tabular}{|c|c|c|c|c|c|}
\hline Run & $\begin{array}{l}\text { Modern } \\
\text { (mean) }\end{array}$ & $\begin{array}{l}\text { Quality } \\
\text { (mean) }\end{array}$ & $\begin{array}{c}\text { Durable } \\
\text { (mean) }\end{array}$ & $\begin{array}{c}\text { Ease of } \\
\text { drinking } \\
\text { (mean) }\end{array}$ & $\begin{array}{c}\text { Ease of handle } \\
\text { (mean) }\end{array}$ \\
\hline 1 & 1.87 & 4.83 & 3.63 & 3.70 & 4.33 \\
\hline 2 & 3.16 & 3.67 & 2.47 & 3.63 & 3.97 \\
\hline 3 & 3.47 & 2.33 & 2.63 & 2.43 & 2.57 \\
\hline 4 & 2.33 & 3.53 & 4.57 & 4.67 & 4.53 \\
\hline 5 & 3.10 & 4.03 & 2.33 & 3.67 & 4.30 \\
\hline 6 & 3.47 & 3.73 & 2.47 & 3.47 & 3.73 \\
\hline 7 & 2.63 & 3.20 & 2.13 & 4.53 & 4.23 \\
\hline 8 & 3.67 & 3.93 & 2.37 & 3.77 & 4.23 \\
\hline 9 & 3.47 & 3.33 & 2.37 & 3.43 & 4.67 \\
\hline 10 & 3.77 & 3.43 & 3.33 & 3.47 & 3.47 \\
\hline 11 & 3.47 & 2.53 & 4.40 & 2.77 & 2.77 \\
\hline 12 & 2.33 & 4.06 & 3.10 & 3.10 & 2.47 \\
\hline 13 & 4.53 & 3.13 & 2.63 & 3.47 & 4.33 \\
\hline 14 & 3.20 & 2.43 & 3.97 & 2.77 & 2.63 \\
\hline 15 & 2.57 & 4.33 & 4.03 & 3.73 & 3.47 \\
\hline 16 & 3.23 & 2.83 & 3.13 & 2.90 & 2.50 \\
\hline 17 & 3.73 & 2.63 & 2.33 & 3.23 & 3.23 \\
\hline 18 & 2.53 & 3.67 & 2.13 & 3.43 & 3.67 \\
\hline 19 & 2.43 & 3.43 & 4.50 & 4.67 & 4.23 \\
\hline 20 & 4.13 & 2.13 & 3.63 & 2.63 & 3.57 \\
\hline 21 & 3.23 & 3.47 & 2.97 & 4.13 & 2.33 \\
\hline 22 & 3.63 & 3.13 & 2.13 & 3.47 & 4.23 \\
\hline 23 & 2.23 & 3.43 & 4.13 & 4.33 & 2.33 \\
\hline 24 & 2.13 & 4.67 & 3.07 & 3.43 & 3.67 \\
\hline 25 & 2.43 & 3.43 & 2.23 & 3.67 & 2.43 \\
\hline 26 & 3.50 & 2.47 & 4.37 & 2.67 & 1.77 \\
\hline
\end{tabular}

\subsection{Response optimization}

In order to consider shape design parameters of wine glass for the five emotions or Kansei words, the shape parameters were optimized by the Minitab optimizer. The optimum response level was defined to get maximum extraction. The analysis results can be summarized in Table 5. Figure 6 shows the shape parameter design models using KE and RSM approach. Control parameters for the optimization of customer impression variables are shown in Table 6. The goal was expected to be maximal, so the upper limit was not set. The lower limit of all responses was set at 1 whereas the target value was set at 5 regarding five level of Likert scale. The weight factors range between 0.1 and 10 with the larger ones relating to more significant responses. The importance of the goals can be arranged sequentially according to increasing importance. In this study, the weight and importance value of each response were both set at 1 meaning all responses are equally important. Response optimization results are shown in Fig. 7. The values in the red line were the optimal value with an overall desirability value of 0.7752 . When the rim's width, the bowl's width, the bowl's height and the stem's height were controlled at $90 \mathrm{~mm}, 61.82 \mathrm{~mm}, 126.67 \mathrm{~mm}$, and $61.97 \mathrm{~mm}$ respectively, the predicted emotion value of modern was at 2.78 (acceptability=55.69\%), the predicted emotion value of quality was at 3.63 (acceptability $=72.57 \%$ ), the predicted emotion value of durable was at 4.14 (acceptability=82.87\%), the predicted emotion value of ease of drinking was at $4.55 \quad$ (acceptability=91.11\%), and the predicted emotion value of ease of handle was at 4.59 (acceptability=91.77\%). In summary, the optimal model of wine glass design that could contains aesthetic quality values of modern, quality, durable, ease of drinking and ease of handle was shown in Fig.8. 
Table 4 ANOVA test for response.

\begin{tabular}{|c|c|c|c|c|c|c|}
\hline$Y$ & Source & $\mathrm{DF}$ & $\begin{array}{c}\text { Adjusted } \\
\text { sums of } \\
\text { squares }\end{array}$ & $\begin{array}{c}\text { Adjusted } \\
\text { Mean Square }\end{array}$ & $F$ value & $p$ value \\
\hline$Y_{1}$ & Regression & 14 & 11.0258 & 0.78755 & 21.25 & 0.000 \\
\hline \multirow[t]{5}{*}{ Modern } & Linear & 4 & 3.1139 & 0.77848 & 21.00 & 0.000 \\
\hline & Square & 4 & 6.6252 & 1.65631 & 44.68 & 0.000 \\
\hline & Interaction & 6 & 1.2866 & 0.21443 & 5.78 & 0.006 \\
\hline & Lack-of-Fit & 10 & 0.4037 & 0.04037 & 9.97 & 0.242 \\
\hline & $\mathrm{R}^{2}=96.43 \%$ & \multicolumn{5}{|c|}{ adjusted $\mathrm{R}^{2}=91.89 \%$} \\
\hline$Y_{2}$ & Regression & 14 & 12.0780 & 0.86271 & 24.44 & 0.000 \\
\hline \multirow[t]{5}{*}{ Quality } & Linear & 4 & 6.3110 & 1.57775 & 44.69 & 0.000 \\
\hline & Square & 4 & 5.0586 & 1.26464 & 35.82 & 0.000 \\
\hline & Interaction & 6 & 0.7084 & 0.11807 & 3.34 & 0.040 \\
\hline & Lack-of-Fit & 10 & 0.3833 & 0.03833 & 7.67 & 0.275 \\
\hline & $\mathrm{R}^{2}=96.89 \%$ & \multicolumn{5}{|c|}{ adjusted $\mathrm{R}^{2}=92.92 \%$} \\
\hline$Y_{3}$ & Regression & 14 & 15.4394 & 1.10282 & 5.26 & 0.004 \\
\hline \multirow[t]{5}{*}{ Durable } & Linear & 4 & 9.0189 & 2.25471 & 10.75 & 0.001 \\
\hline & Square & 4 & 5.7787 & 1.44468 & 6.89 & 0.005 \\
\hline & Interaction & 6 & 0.6419 & 0.10698 & 0.51 & 0.789 \\
\hline & Lack-of-Fit & 10 & 2.3037 & 0.23037 & 94.03 & 0.080 \\
\hline & $\mathrm{R}^{2}=87.00 \%$ & \multicolumn{5}{|c|}{ adjusted $\mathrm{R}^{2}=70.46 \%$} \\
\hline$Y_{4}$ & Regression & 14 & 8.29109 & 0.59222 & 5.41 & 0.004 \\
\hline \multirow[t]{5}{*}{ Ease of drinking } & Linear & 4 & 2.21508 & 0.55377 & 5.06 & 0.015 \\
\hline & Square & 4 & 5.43308 & 1.35827 & 12.41 & 0.000 \\
\hline & Interaction & 6 & 0.64292 & 0.10715 & 0.98 & 0.483 \\
\hline & Lack-of-Fit & 10 & 1.20412 & 0.12041 & 2408.25 & 0.016 \\
\hline & $\mathrm{R}^{2}=87.32 \%$ & \multicolumn{5}{|c|}{ adjusted $\mathrm{R}^{2}=71.18 \%$} \\
\hline$Y_{5}$ & Regression & 14 & 16.3238 & 1.16599 & 7.77 & 0.001 \\
\hline \multirow[t]{5}{*}{ Ease of handle } & Linear & 4 & 8.5467 & 2.13668 & 14.24 & 0.000 \\
\hline & Square & 4 & 7.5506 & 1.88764 & 12.58 & 0.000 \\
\hline & Interaction & 6 & 0.2265 & 0.03775 & 0.25 & 0.949 \\
\hline & Lack-of-Fit & 10 & 1.5999 & 0.15999 & 3.12 & 0.416 \\
\hline & $\mathrm{R}^{2}=90.81 \%$ & \multicolumn{5}{|c|}{ adjusted $\mathrm{R}^{2}=79.12 \%$} \\
\hline
\end{tabular}

Table 5 Response optimization of shape design parameters for each Kansei word.

\begin{tabular}{|c|c|c|c|c|c|}
\hline \multirow[t]{2}{*}{ Kansei word } & Composite & $\mathrm{A}$ & B & $\mathrm{C}$ & $\mathrm{D}$ \\
\hline & $\begin{array}{c}\text { desirability } \\
\text { (D) }\end{array}$ & $\begin{array}{l}\text { the rim's } \\
\text { width (mm) }\end{array}$ & $\begin{array}{l}\text { the bowl's } \\
\text { width (mm) }\end{array}$ & $\begin{array}{l}\text { the bowl's } \\
\text { height (mm) }\end{array}$ & $\begin{array}{l}\text { the stem's } \\
\text { height (mm) }\end{array}$ \\
\hline $\operatorname{Modern}\left(Y_{l}\right)$ & 1.0000 & 120 & 30 & 180 & 85 \\
\hline Quality $\left(Y_{2}\right)$ & 1.0000 & 100.91 & 120 & 180 & 85 \\
\hline Durable $\left(Y_{3}\right)$ & 0.9505 & 50.91 & 77.27 & 128.28 & 55.30 \\
\hline Ease of drinking $\left(Y_{4}\right)$ & 0.9306 & 83.64 & 70 & 102.42 & 52.88 \\
\hline Ease of handle $\left(Y_{5}\right)$ & 0.9027 & 97.27 & 69.09 & 104.04 & 60.76 \\
\hline
\end{tabular}




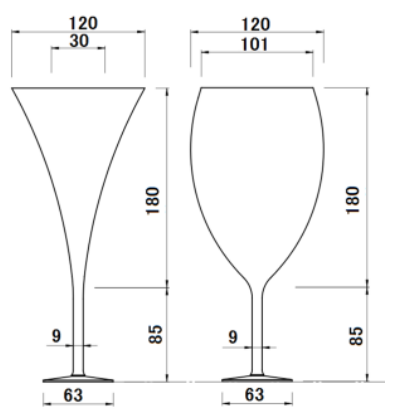

(a) (b)

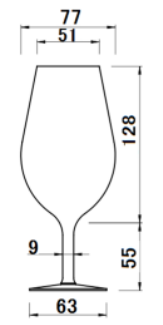

(c)

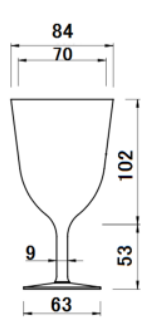

(d)

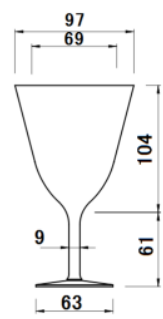

(e)

Fig. 6 Optimal models of wine glass for each Kansei word.

(a) modern (b) quality (c) durable (d) ease of drinking (e) ease of handle

Table 6 Parameters of the response optimization.

\begin{tabular}{llccccc}
\hline \hline Response & Goal & Lower & Target & Upper & Weight & importance \\
\hline Modern $\left(Y_{1}\right)$ & Maximize & 1 & 5 & - & 1 & 1 \\
\hline Quality $\left(Y_{2}\right)$ & Maximize & 1 & 5 & - & 1 & 1 \\
\hline Durable $\left(Y_{3}\right)$ & Maximize & 1 & 5 & - & 1 & 1 \\
\hline Ease of drinking $\left(Y_{4}\right)$ & Maximize & 1 & 5 & - & 1 & 1 \\
\hline Ease of handle $\left(Y_{5}\right)$ & Maximize & 1 & 5 & - & 1 & 1 \\
\hline \hline
\end{tabular}

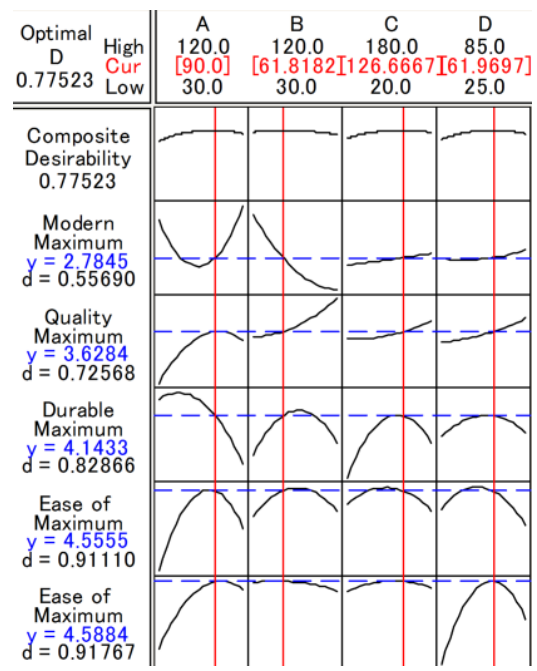

Fig. 7 Response optimization of all of five Kansei words

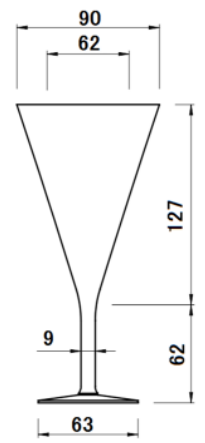

Fig. 8 Optimal model of wine glass for all Kansei words 


\section{Conclusion}

This study illustrates the application of KE and RSM-BBD for optimization of shape design parameters. KE was used to evoke costumer feelings and emotions by evaluation of Kansei words. The RSM-BBD was successfully applied to estimate the optimal design parameters for the extraction of customer emotion or Kansei words. The effects of four shape parameters of wine glass, namely the rim's width, the bowl's width, the bowl's height and the stem's height on the surface potential of five Kansei words, namely modern, quality, durable, ease of drinking and ease of handle were examined. Afterward, based on all findings and results, the optimal model was designed. The result of this study provides useful understanding for shape product design and shows that these techniques can be applied to other products. Finally, the product designers can be utilized it to translate customers' emotions into product attributes.

\section{References}

Aslan N. and Cebeci Y., Application of Box-Behnken design and response surface methodology for modeling of some Turkish coals, Fuel, Vol. 86 (2007), pp. 90-97.

ASQ, Quality Glossary-A (online), available from < http://asq.org/glossary/a.html>, (accessed on 15May, 2015).

Bandyopadhyay S. and Bhattacharya R., Discrete and continuous simulation theory and practice (2014), pp.305-307, CRC Press, Boca Raton, FL.

Box G.E.P. and Behnken D.W., Some new three level designs for the study of quantitative variables, Technometrics, Vol. 2, No.4 (1960), pp. 455-475.

Box G.E.P. and Wilson K.B., On the experiment attainment of optimum conditions, Journal of the Royal Statistical Society, Vol.13, No.1 (1951), pp.1-45.

Chen C.C. and Chuang M.C., Integrating the Kano model into a robust design approach to enhance customer satisfaction with product design, International Journal of Production Economics, Vol. 114 (2008), pp. 667-681.

Drouart E. and Alarie N., Influence of cultural differences on marketing cars to U.S. and Japanese consumers, Proceedings of Annual Paris Business and Social Science Research Conference 2013 (online), available from <http://www.wbiworldconpro.com/uploads/paris-conference-2013/marketing/1372567328_531-Eric.pdf>, (accessed on 31 July, 2015).

Ferreira S.L.C., Bruns R.E., Ferreira H.S., Matos G.D., David J.M., G.C. Brandão, da Silva E.G.P., Portugal L.A., dos Reis P.S., Souza A.S. and dos Santos W.N.L., Box-Behnken design: An alternative for the optimization of analytical methods, Analytica Chimica Acta, Vol. 597 (2007), pp. 179-186.

Fu H.Y., Xu P.C., Huang G.H., Chai T.C., Hou M. and Gao P.F., Effects of aeration parameters on effluent quality and membrane fouling in a submerged membrane bioreactor using Box-Behnken response surface methodology, Desalination, Vol.302 (2012), pp. 33-42.

Hasan S.Y., Ranjan D. and Talat M., Water hyacinth biomass (WHB) for the biosortion of hexavalent chromium: optimization of process parameters, BioResources, Vol.5, No.2 (2010) pp. 563-575.

Lai H.H., Chang Y.M. and Hua-Cheng Chang H.C., A robust design approach for enhancing the feeling quality of a product: a car profile case study, International Journal of Industrial Ergonomics, Vol. 35 (2005), pp. 445-460.

Lai Y., Huang H., Huang Q., Zhang H. and Guo Z., Optimization of the experimental conditions for the synthesis of micro-size monodisperse spherical silver powders using Box-Behnken design, Powder Technology, Vol.263 (2014), pp. 7-13.

Lanzotti A., Tarantino P. and Matrone G., An empirical approach to optimal experimental design selection and data analysis for the synthesis phase of Kansei Engineering (online), available from <www.ep.liu.se/ecp/033/014/ecp0803314.pdf >, (accessed on 16 May, 2015).

Minitab, User manual of Minitab statistical software (2010), Minitab Inc., U.S.A.

Mo Y., Zhao L., Wang Z., Chen C.L., Tan G.Y.A. and Wang J.Y., Enhanced styrene recovery from waste polystyrene pyrolysis using response surface methodology coupled with Box-Behnken design, Waste Management, Vol.34, No.4 (2014), pp. 763-769.

Moradi M., Daryan J.T. and Mohamadalizadeh A., Response surface modeling of $\mathrm{H}_{2} \mathrm{~S}$ conversion by catalytic oxidation reaction over catalysts based on $\mathrm{SiC}$ nanoparticles using Box-Behnken experimental design, Fuel Processing Technology, Vol. 109 (2013), pp. 163-171. 
Myers R.H. and Montgomery D.C., 2nd ed., Response surface methodology: Process and product optimization using designed experiments (2002), ch.1. John Wiley \& Sons Inc., U.S.A.

Nagamachi M., Kansei engineering: a new ergonomic consumer-oriented technology for product development, International Journal of Industrial Ergonomic, Vol.15, No. (1995), pp. 3-11.

Nagamachi M., Kansei/Affective Engineering (2011), pp.31-225, CRC Press, Boca Raton, Fla, USA.

Nordgren A., Exploring automotive shape with Kansei design- Asystematic approach to building design support systems with shape sensibility (online), available from <http://iroha.scitech.lib.keio.ac.jp:8080/sigma/bitstream/handle/10721/2187/document.pdf?sequence=2>, (accessed on 16 May, 2015).

Nordgren A. and Aoyama H., Style design method based on form impressions, Proceeding of ASME International Design Engineering Technical Conferences and Computers and Information in Engineering Conference (2005), pp. 5-12.

Petiot J.F. and Yannou B., How to comprehend and assess product semantics- a proposal for an integrated methodology, Proceeding of International conference on engineering design (ICED03) (2003), pp.1-10.

Schütte S., Designing feelings into products: integrating Kansei engineering methodology in product development, Thesis (2002), Dep. Mechanical Eng., Linkopings University, Linkoping, Sweden.

Schütte S., Engineering emotional values in product design: Kasei engineering in development, Ph.D. dissertation (2005), Dep. Mechanical Eng., Linkopings University, Linkoping, Sweden.

Schütte S., Evaluation of the affective coherence of the exterior and interior of chocolate snacks, Food Quality and Preference, Vol. 29, No.1 (2013), pp.16-24.

Schütte S. and Eklund J., Design of rocker switches for work-vehicles an application of Kansei Engineering, Applied Ergonomics, Vol.36, No.5 (2005), pp. 557-567.

Shieh M.D. and Yeh Y.E., Developing a design support system for the exterior form of running shoes using partial least squares and neural networks, Computers \& Industrial Engineering, Vol. 65, No.4 (2013), pp. 704-718.

Small and medium industrial institute, Glass industry report of 2011 (online), available from <www.smi.or.th/index.php/sample-sites.../7-aec? >, (accessed on 31 July, 2015), (in Thai).

Sutono S.B., Taha Z., Rashid S.H.A., Aoyama H. and Subagyo, Application of robust design approach for design parameterization in Kansei engineering, Advanced Materials Research, Vol. 479-481 (2012), pp. 1670-1680.

Swamy G.J., Sangamithra A. and Chandrasekar V., Response surface modeling and process optimization of aqueous extraction of natural pigments from Beta vulgaris using Box-Behnken design of experiments, Dyes and Pigments, Vol. 11 (2014), pp. 64-74.

Tang C.Y., Fung K.Y., Lee Eric W.M., Ho G.T.S., Kin W.M. S. and Mou W.L., Product form design using customer perception evaluation by a combined super ellipse fitting and ANN approach, Advanced Engineering Informatics, Vol. 27, No.3 (2013), pp.386-394.

Webstaurantstore, Type of wine glasses (online), available from <http://www.webstaurantstore.com/guide/580/types-of-wine-glasses.html>, (accessed on 12 May, 2015).

Widiyati K. and Aoyama H., A study of Kansei engineering in PET bottle silhouette, Proceeding of ASME International Design Engineering Technical Conferences and Computers and Information in Engineering Conference (2011), pp. 849-858.

Wikipedia, (2015a), F-test (online), available from < http://en.wikipedia.org/wiki/F-test>, (accessed on 12 May, 2015).

Wikipedia, (2015b), Kansei engineering (online), available from 〈http://en.wikipedia.org/wiki/Kansei_engineering >, (accessed on 12 May, 2015).

Yadav H.C., Jain R., Singh A. R. and Mishra P. K., Aesthetical design of a car profile: a Kano model-based hybrid approach, International Journal of Advanced Manufacturing Technology, Vol. 67 (2013), pp.2137-2155.

Yanagisawa H. and Fukuda S., Design optimization for customers' KANSEI requirement: application of interactive reduct evolutional computation to industrial design with curves, International Journal of Manufacturing Technology and Management, Vol.10, No.4 (2007), pp.360-379. 